\title{
EDITORIAL
}

\section{WHY SHOULD PLASMA TRANSTHYRETIN BECOME A ROUTINE SCREENING TOOL IN ELDERLY PERSONS?}

\author{
Y. INGENBLEEK
}

Laboratory of Nutrition, Faculty of Pharmacy, University Louis Pasteur Strasbourg 1, France

The homotetrameric transthyretin (TTR) molecule $(55 \mathrm{kDa}$ as $\mathrm{MM})$ was first identified in cerebrospinal fluid (CSF) (1) and later in human serum (2). The initial name of prealbumin (PA) arose from the observation that the protein was migrating in front of the serum-albumin (ALB) peak in currently used electrophoretic systems. PA was rapidly recognized as one of the 3 specific binding proteins (BPs) involved in the transport of thyroid hormones (3) and of plasma retinol through the mediation of the small retinol-binding protein (RBP, $21 \mathrm{kDa}$ as MM) (4). The more physiologically informative TTR denomination was adopted in 1981 (5), emphasizing the dual conveying role played by the BP in biological fluids. The aim of the present editorial is to rapidly describe the main properties exerted by TTR and its potential applicability in elderly persons in the light of recent findings.

There exists at least 3 good reasons why TTR should become a routine medical screening test in elderly persons. The first is grounded on the assessment of protein nutritional status that is frequently compromized and may become a lifethreatening condition (6). TTR was proposed as marker of protein-energy malnutrition (PEM) in 1972 (7). As a result of protein and energy deprivation, TTR hepatic synthesis is suppressed (8) whereas all plasma indispensable aminoacids (IAAs) manifest declining trends (9) with the sole exception of methionine (Met) whose concentration usually remains unmodified (10). By comparison with ALB and transferrin (TF) plasma values, TTR did reveal a much higher degree of reactivity to changes in protein status that has been attributed to its shorter biological half-life and to its unusual tryptophan richness (11). In the declared stage of PEM, multivariate analyses have disclosed that the predictive ability of outcome offered by TTR is independent of that provided by ALB and TF (12). Uncomplicated PEM primarily affects the size of body nitrogen $(\mathrm{N})$ pools, allowing to reduce protein syntheses to levels compatible with survival. These adaptive changes are faithfully identified by the serial measurement of TTR whose reliability has never been disputed in protein-depleted states. On the contrary, the nutritional relevance of TTR has been controverted in acute and chronic inflammatory conditions due to the cytokine-induced transcriptional blockade of its liver synthesis (13) which is an obligatory step occurring independently from the prevailing nutritional status. Although PEM and stressful disorders refer to distinct pathogenic mechanisms, their combined inhibitory effects on TTR liver

Received October 11, 2008

Accepted for publication November 5, 2008 production rate did fuel a long-lasting strife (14) and explain the reluctance expressed by some workers towards a parameter regarded as endowed with high sensitivity but poor specificity. Recent body composition studies have nevertheless contributed to disentangle these intermingled morbidities, showing that the evolutionary patterns displayed by plasma TTR are closely correlated with the fluctuations of lean body mass (LBM), whatever the nutritional or inflammatory factors involved. In other words, the actual TTR plasma level reflects the alterations of LBM which encompasses both facets of any morbid condition (15). These integrative aspects render obsolete the previous quarrel and restore to TTR its full reliability (16). It must nevertheless be kept in mind that nutritional and inflammatory factors working in varying proportions may lead to proximate biochemical results, making hard to assess the role played by each component. Hence the proposal to set up a comprehensive formula comprising several indicators of the disease spectrum. The so-called prognostic inflammatory and nutritional index (PINI), which possesses the capacity to grade the severity of any disease process, has been successfully applied to the aged population (17), consistent with more than 100 already published PINI investigations covering most medical disciplines.

The second reason follows from recent advances describing the unexpected relationship established between TTR and homocysteine (Hcy), a S-containing AA not found in customary diets but resulting from the endogenous transmethylation of dietary Met. Hcy may be recycled to Met along a remethylation pathway (RM) or irreversibly degraded throughout the transsulfuration (TS) cascade to release sulfaturia as end-product (18). Hcy is thus situated at the crossroad of RM and TS pathways which are in equilibrium keeping plasma Met values unaltered (19). Three dietary watersoluble B vitamins are implicated in the regulation of the Hcy-Met cycle. Folates (vit B9) are the most powerful agent, working as supplier of the methyl group required for the RM process whereas cobalamins (vit B12) and pyridoxine (vit B6) operate as co-factors of Met-synthase and cystathionine- synthase ( $\mathrm{C}$ S), respectively. Met-synthase enzyme promotes the RM pathway whereas the rate-limiting C S enzyme governs the TS degradative cascade $(18,19)$. Dietary deficiency in any of the 3 vitamins may upregulate Hcy plasma values, an acquired biochemical anomaly increasingly encountered in aged populations $(20,21)$, responsible for 
thrombovascular complications with growing public health impact $(22,23)$ and often associated with neurodegenerative disorders (24). Several stepwise multiple regression analyses have nevertheless documented that the effect of the 3 watersoluble vitamins, taken together, usually account for no more than $50 \%$ of the Hcy variance (25). This situation has prompted the search for other causal factor(s) which might fill the gap between the recorded epidemiological data and the vitamin triad deficiency currently incriminated. Recent data have shown that the metabolisms of $\mathrm{S}$ and $\mathrm{N}$ are narrowly correlated and that both elements coexist within constant but different mean ratios in animal tissues and plant products (1:14.5 versus $1: 20$ to $1: 35$, respectively) (26). This last proportion does not optimally fulfills human body requirements, implying that strict vegans are permanently at risk of incuring $\mathrm{N}$ - and $\mathrm{S}$-deficiencies. Moreover, any acute or chronic disorder causes cytokine-induced tissue proteolysis documented by urinary leakage of tightly correlated amounts of $\mathrm{N}$ - and S-catabolites $(27,28)$, attesting that total body $\mathrm{N}(\mathrm{TBN})$ and total body $\mathrm{S}$ (TBS) pools are exhausted concomitantly. Here too, depletion of $\mathrm{N}$ and $\mathrm{S}$ reserves may generate a threatening situation that is prevented by an acquired impairment of $\mathrm{C} \beta \mathrm{S}$ activity favoring the upstream retention of Hcy molecules that stimulates Hcy $\rightarrow$ Met conversion. In contrast to all other IAAs, the preservation of normal methioninemia implies high metabolic priority best explained by the roles played by Met in the synthesis of S-containing molecules of survival importance and in the production of a myriad of S-compounds with significant molecular, structural and functional properties (28). Hyperhomocysteinemia thus appears as the dark side of efforts provided by $\mathrm{N}$ - and $\mathrm{S}$ depleted individuals to maintain Met homeostasis. Of utmost importance is the finding that plasma TTR concentrations are negatively correlated with rising Hcy values $(25,28)$, allowing to detect those subclinically malnourished patients with borderline TBN and TBS status who are more at risk of developing the metabolic disease. Complementarily to the watersoluble vitamin B-deprivation concept, the S-deficiency theory thus provides an unifying concept for the main nutritional factors involved in the epidemiology of hyperhomocysteinemia.

Last but not least, the third reason refers to recent and fascinating data recorded in neurobiology and emphasizing the specific properties of TTR in the prevention of brain deterioration. TTR participates directly to the maintenance of memory and normal cognitive processes during the ageing process by acting on the retinoid signalling pathway $(29,30)$. Moreover, TTR may bind amyloid $\beta$-peptide in vitro, preventing its transformation into toxic amyloid fibrils and amyloid plaques (31). TTR works as a limiting factor for the plasma transport of retinol (32) which in turn operates as a ratelimiting determinant of both physiologically active retinoic acid (RA) derivatives (33), implying that any fluctuation in protein status might well entail corresponding alterations in cellular bioavailability of retinoid compounds. Under normal ageing circumstances, the concentration of retinoid compounds declines in cerebral tissues (34) together with the downregulation of RA receptor expression (35). In animal models, depletion of RAs causes the deposition of amyloid $\beta$ peptides, favoring the formation of amyloid plaques (36). On the contrary, exogenous administration of RAs restores the expression of retinoid receptors and maintains the activity of proteins involved in the control of amyloidogenic pathways (37). In addition, it is shown that retinol may disaggregate preformed amyloid $\beta$-fibrils more efficiently than do RAs (38), showing that retinol and RAs work synergistically to prevent the deterioration of cerebral tissues. TTR, RBP, retinol and RAs are all effector molecules diffusing in CSF and involved in the growth and maturation of brain activities. TTR is a major protein found in CSF that may be produced either by the choroid plexus - a stable secretory process that is poorly sensitive to extracerebral influences and allows even distribution of thyroxine to neural tissues (39) - or derived from the bloodstream after having crossed the blood-brain-barrier ( BBB) conveying system (40). The minute amounts of RBP and retinol measured in CSF apparently follow the same BBB crossing process (40). Thyroid hormones and retinoids function in concert through the mediation of common heterodimeric motifs bound to DNA response elements (41). Taken together, the data suggest that any protein-depleted state, resulting either from dietary $\mathrm{N}$-insufficiency or excessive hypercatabolic $\mathrm{N}$ losses, should depress the liver production and CSF delivery of both TTR and RBP molecules. The fact that AD patients are frequently found malnourished (42) likely renders an account of their low TTR $(43,44)$ and RBP (45) intrathecal concentrations whose decline is negatively correlated with disease severity and progression. Other neurological disorders such as depressive behavior (46), schizophrenia (47) and Guillain-Barré syndrome (48) are reportedly characterized by comparable decline in intrathecal TTR and RBP values, suggesting that inappropriate nutritional status might well contribute to worsen several cerebral disorders. The lesson to learn from these recent findings is that optimal protein nutritional status, as assessed by the maintenance of plasma TTR, RBP and retinol concentrations within normal ranges, is probably the best physiological way to prevent or to stem neurodegenerative processes (40).

Financial disclosure: None of the authors had any financial interest or support for this paper.

\section{References}

1. Kabat EA, Moore D, Landow H. An electrophoretic study of the protein components in cerebrospinal fluid and their relationship to serum proteins. J Clin Invest 1942; 21:571-577

2. Schultze HE, Schönenberger M, Schwick G. Über ein präalbumin des menschlichen serums. Biochem Z 1956; 328:267-284.

3. Ingbar SH. Prealbumin : a thyroxine binding protein of human plasma. Endocrinology 1958; 63:256-259.

4. Kanai M, Raz A, Goodman DS. Retinol-binding protein : the transport protein for vitamin A in human plasma. J Clin Invest 1968; 47:2025-2044 


\section{EDITORIAL}

5. Goodman DS, Peters T, Robbins J, Schwick G. Prealbumin becomes transthyretin Nomenclature Committee-IUB and JCBN Newsletter. J Biol Chem 1981;256:12-14. 6. Constans T, Bacq Y, Bréchot JF, Guilmot JL, Choutet P, Lamisse F. Protein-energy malnutrition in elderly medical patients. J Am Geriatr Soc 1992; 40:263-268.

7. Ingenbleek Y, De Visscher M, De Nayer P. Measurement of prealbumin as index of protein-calorie malnutrition. Lancet 1972; ii:106-109.

8. Strauss DS, Marten NW, Hayden JM, Burke EJ. Protein restriction decreases the abundance of serum albumin and transthyretin nuclear transcripts in rat liver. J Nut $1994 ; 124: 1041-1051$

9. Polge A, Bancel E, Bellet H, Strubel D, Porey S, Peray P, Carlet C, Magnan de Bornier B. Plasma amino acid concentrations in elderly patients with protein energy malnutrition. Age Ageing 1997; 26:457-462.

10. Ingenbleek $\mathrm{Y}$, Barclay $\mathrm{D}$, Dirren $\mathrm{H}$. Nutritional significance of alterations in serum amino acid patterns in goitrous patients. Am J Clin Nutr 1986; 43:310-319.

11. Ingenbleek Y, Van den Schrieck HG, De Nayer P, De Visscher M. Albumin transferrin and the thyroxine-binding prealbumin / retinol-binding protein complex in assessment of malnutrition. Clin Chim Acta 1975; 63:61-67.

12. Brasseur D, Hennart P, Dramaix M, Bahwere P, Donnen O, Tonglet R, Devreker T, Duchateau J. Biological risk factors for fatal protein energy malnutrition in hospitalized children in Zaire. J Pediatr Gastroenterol Nutr 1994; 18:220-224.

13. Murakami T, Ohnishi S, Nishiguchi S, Maeda S, Araki S, Shimada K. Acute-phase response of mRNAS for serum amyloid P component, C-reactive protein and prealbumin (transthyretin) in mouse liver. Biochem Biophys Res Commun 1988; 155:554-560.

14. Johnson AM. Low levels of plasma proteins : malnutrition or inflammation ? Clin Chem Lab Med 1999; 37:91-96

15. Ingenbleek Y. Plasma transthyretin reflects the fluctuations of lean body mass in health and disease. In : Recent advances in transthyretin evolution, structure and biological functions, Richardson S, Cody V, eds. Springer Verlag : Berlin, 2009 (in press).

16. Sergi G, Coin A, Enzi G, Volpato S, Inelmen EM, Buttarello M, Peloso M, Mulone $\mathrm{S}$, Marin S, Bonometto M. Role of visceral proteins in detecting malnutrition in the elderly. Eur J Clin Nutr 2006; 60:203-209.

17. Bonnefoy M, Ayzac L, Ingenbleek Y, Kostka T, Boisson RC, Bienvenu J. Usefulness of the prognostic inflammatory and nutritional index (PINI) in hospitalized elderly persons. Int J Vitam Nutr Res 1998; 68:189-195.

18. Finkelstein JD. Homocysteine : a history in progress. Nutr Rev 2000; 58: 193 204

19. Finkelstein JD, Martin JJ. Methionine metabolism in mammals. Distribution of methionine between competing pathways. J Biol Chem 1984; 259: 9508-9513.

20. Bates CJ, Mansoor MA, van der Pols J, Prentice A, Cole TJ, Finch S. Plasma total homocysteine in a representative sample of 972 British men and women aged 65 and over. Eur J Clin Nutr 1997; 51: 691-697.

21. Koehler KM, Romero IJ, Stauber PM, Parco-Tubbeh SL, Liang HC, Baumgartne RN, Garry PJ, Allen RH, Stabler SP. Vitamin supplementation and other variables affecting serum homocysteine and methylmalonic acid concentrations in elderly men and women. J Am Coll Nutr 1996; 15: 364-376.

22. Hankey GJ, Eikelboom JW. Homocysteine and vascular disease. Lancet 1999; 354 407-413.

23. Welsch GN, Loscalzo J. Homocysteine and atherothrombosis. N Eng J Med 1998; 338: 1042-1050.

24. McCaddon A, Davies G, Hudson P, Tandy S, Cattell H. Total serum homocysteine in senile dementia of Alzheimer's type. Int J Geriatr Psychiatr 1998; 13: 235-239.

25. Ingenbleek $\mathrm{Y}$, Hardillier E, Jung L. Subclinical protein malnutrition is a determinant of hyperhomocysteinemia. Nutrition 2002; 18:40-46.

26. Ingenbleek Y. The nutritional relationship linking sulfur to nitrogen in living organisms. J Nutr 2006; 136: S1641-S1651.

27. Cuthbertson DP. The distribution of nitrogen and sulphur in the urine during conditions of increased catabolism. Biochem J 1931; 25: 236-244.

28. Ingenbleek Y, Young VR. The essentiality of sulfur is closely related to nitrogen metabolism. Nutr Res Rev 2004; 17: 135-151.

29. Brouillette J, Quirion R. Transthyretin : A key gene involved in the maintenance of memory capacities during aging. Neurobiol Aging 2007; 29: 1721-1732

30. Sousa JC, Marques F, Dias-Ferreira E, Cerqueira JJ, Sousa N, Palha JA Transthyretin influences spatial reference memory. Neurol Learn Mem 2007 88:381-385.

31. Schwarzman AL, Gregori L, Vitek MP, Lyubski S, Strittmatter WJ, Enghilde JJ, Bhasin R, Silverman J, Weisgraber KH, Coyle PK, Zagorski MG, Talafous J, Eisenberg M, Saunders AM, Roses AD, Goldgaber D. Transthyretin sequesters amyloid protein and prevents amyloid formation. Proc Natl Acad Sci USA 1994: 91:8368-8372.

32. Ingenbleek Y, Van den Schrieck HG, De Nayer P, De Visscher M. The role of retinol-binding protein in protein-calorie malnutrition. Metabolism 1975; 24:633641.

33. Fex GA, Larsson K, Nilsson-Ehle I. Serum concentrations of all-trans and 13-cis retinoic acid and retinol are closely correlated. J Nutr Biochem 1996; 7:162-165.

34. Goodman AB, Pardee AB. Evidence for defective retinoid transport and function in late onset Alzheimer's disease. Proc Natl Acad Sci USA 2003; 100:2901-2905.

35. Etchamendy N, Enderlin V, Marighetto A, Vouimba RM, Pallet V, Jaffard R, Higueret P. Alleviation of a selective age-related relational memory deficit in mice by pharmacologically induced normalization of brain retinoid signaling. J Neurosci $2001 ; 21: 6423-6429$.

36. Corcoran JPT, So PL, Maden M. Disruption of the retinoid signalling pathway cause a deposition of amyloid beta in the adult rat brain. Eur J Neurosci 2004; 20: 896-902.

37. Husson M, Enderlin V, Delacourte A, Ghenimi N, Alfos S, Pallet V, Higueret P. Retinoic acid normalizes nuclear receptor mediated hypo-expression of protein involved in beta-amyloid deposits in the cerebral cortex of vitamin A deprived rats. Neurobiol Dis 2006; 23:1-10

38. Ono K,Yoshiike Y, Takashima A, Hasegawa K, Naiki H, Yamada M. Vitamin A exhibits potent antiamyloidogenic and fibril-stabilizing effects in vitro. Exp Neurol 2004; 189: 380-392.

39. Dickson PW, Aldred AR, Marley PD, Bannister D, Schreiber G. Rat choroid plexu specializes in the synthesis and secretion of transthyretin (prealbumin). Regulation of transthyretin synthesis in choroid plexus is independent from that in liver. J Biol Chem 1986; 261: 3475-3478

40. Ingenbleek Y. Plasma transthyretin indicates the direction of both nitrogen balance and retinoid status in health and disease. Open Clin Chem J 2008; 1:1-12.

41. Blomhoff R, Blomhoff HK. Overview of retinoid metabolism and function. J Neurobiol 2006; 66:606-630

42. Sandman PO, Adolfsson R, Nygren C, Hallmans G, Windblad B. Nutritional statu and dietary intake in institutionalized patients with Alzheimer's disease and multiinfarct dementia. J Am Geriatr Soc 1987; 35: 31-38.

43. Riisøen H. Reduced prealbumin (transthyretin) in CSF of severely demented patients with Alzheimer's disease. Acta Neurol Scand 1988; 78: 455-459.

44. Gloeckner SF, Meyne F, Wagner F, Heinemann U, Krasnianski A, Meissner B, Zer I. Quantitative analysis of transthyretin, tau and amyloid-beta in patients with dementia. J Alzheimers Dis 2008; 14:17-25.

45. Jung SM, Lee K, Lee JW, Namkoong H, Kim HK, Kim S, Na HR, Ha SA, Kim JR, Ko J, Kim JW. Both plasma retinol-binding protein and haptoglobin precursor allele 1 in CSF : candidate biomarkers for the progression of normal to mild cognitive impairment to Alzheimer's disease. Neurosci Lett 2008; 436: 153-157.

46. Sullivan GM, Hatterer JA, Herbert J, Chen X, Roose SP, Attia E, Mann JJ, Marangell LB, Goetz RR, Gorman JM. Low levels of transthyretin in the CSF of depressed patients. Am J Psychiatry 1999; 156: 710-715.

47. Wan C, Yang Y, Li H, La Y, Zhu H, Jiang L, Chen Y, Feng G, He L. Dysregulation of retinoid transporters expression in body fluids of schizophrenia patients. J Proteome Res 2006; 5: 3213-3216.

48. Yang YR, Liu SL, Qin ZY, Liu FJ, Qin YJ, Bai SM, Chen ZY. Comparative proteomics analysis of cerebrospinal fluid of patients with Guillain-Barré syndrome. Cell Mol Neurobiol 2008; 28: 737-744. 